\title{
Two distinct mechanisms localise cyclin B transcripts in syncytial
}

\section{Drosophila embryos}

\author{
JORDAN W. RAFF*, WILLIAM G. F. WHITFIELD and DAVID M. GLOVER $\dagger$ \\ Cancer Research Campaign Laboratories, Cell Cycle Genetics Group, Department of Biochemistry, Medical Sciences Institute, The \\ University, Dundee DDI $4 H N$, Scotland \\ * Present address: Department of Biochemistry and Biophysics, University of California, San Francisco, California 94143, USA \\ $\dagger$ Author for correspondence
}

\begin{abstract}
Summary
We demonstrate that two independent mechanisms act on maternally derived cyclin $B$ transcripts to concentrate the transcripts at the posterior pole of the Drosophila oocyte and at the cortex of the syncytial embryo. The cortical accumulation occurs because the cyclin B transcript is concentrated around nuclei and comigrates with them to the cortex. The perinuclear localisation of the transcript is blocked by inhibitors of microtubule polymerisation and the transcript colocalises with microtubular structures during the cell cycle, suggesting that the transcript is associated either directly or indirectly with microtubules. Neither microtubules
\end{abstract}

nor actin filaments are required to maintain the posterior concentration of cyclin B transcripts. Instead, this seems to depend on the association of the transcripts with a component of the posterior cytoplasm. The distribution pattern of the transcript at the posterior pole throughout embryogenesis and in a variety of mutant embryos suggests that this component is associated with polar granules.

Key words: cyclins, mRNA localisation, microtubules, polar granules, germ cells, Drosophila.

\section{Introduction}

The cyclins are a family of proteins that accumulate during interphase, and are then rapidly degraded at about the time of the metaphase-anaphase transition (for review see Hunt, 1989; Swenson et al. 1989). This unique temporal pattern suggested that the cyclins might be involved in controlling the entry into and exit from mitosis, a hypothesis that has recently received strong experimental support. First, it has been demonstrated that cyclin synthesis is required for the entry into mitosis and meiosis in a number of systems (Swenson $e t$ al. 1986; Pines and Hunt, 1987; Minshull et al. 1989; Westendorf et al. 1989). Second, in a cell-free extract from Xenopus eggs in which all endogenous mRNA has been destroyed, the addition of cyclin B mRNA reconstitutes the characteristic cycling of cyclin B protein levels, which drives the extract through multiple rounds of mitosis-like events (Murray and Kirschner, 1989). Third, if the cyclin B mRNA that is added to the extract contains a deletion of the region that encodes the first 90 amino acids, the cyclin that is synthesised is not degraded and the extract becomes blocked in mitosis, demonstrating that cyclin destruction is required for the exit from mitosis (Murray et al. 1989).

The DNA sequences encoding the Drosophila homologues of cyclin A and cyclin B have recently been cloned-(Lehner and O'Farrell, 1989; Whitfield et al. 1989). Both proteins show the expected pattern of synthesis and destruction during the cell divisions that take place after cellularisation has occurred at nuclear cycle 14 (Lehner and O'Farrell, 1989, 1990; Whitfield $e t$ al. 1990). The behaviour of the cyclin proteins prior to cellularisation, however, has not been described in any detail. During this period, the nuclei in the syncytial embryo proceed through a very rapid series of nearly synchronous nuclear divisions (Zalokar and Erk, 1976; Foe and Alberts, 1983). At nuclear cycle 7-8, the majority of nuclei, which are initially located in the interior of the embryo, coordinately start to migrate to the embryo cortex. Early in cycle 9, the nuclei reach the cortex at the posterior pole, where they initiate the formation of pole buds. The nuclei in these buds undergo two further rounds of division before they pinch off from the embryo to form pole cells, the future germ cells (Mahowald, 1962; Counce, 1963; Warn et al. 1985). Early in cycle 10 the somatic nuclei reach the cortex where they proceed through three further rounds of division before cellularisation occurs. The cyclins appear to be maintained at high levels throughout these nuclear cycles, and there is no large-scale destruction of the cyclin proteins across the whole syncytium (Lehner 
and O'Farrell, 1989, 1990; Maldonado-Codina and Glover, unpublished data).

The distribution of cyclin transcripts in the Drosophila embryo was described by Whitfield et al. (1989) and Lehner and O'Farrell (1990). Both cyclin A and cyclin $\mathrm{B}$ transcripts are homogeneously distributed in the early embryo, but, in addition, cyclin B transcripts are concentrated at the posterior pole at some time prior to pole bud formation. The cyclin B transcripts at the posterior pole become incorporated into the developing pole cells, where they remain at high levels throughout embryonic development. By nuclear cycle 10-11, when most of the nuclei have migrated to the embryo cortex, the majority of the cyclin B transcript in the rest of the embryo becomes tightly localised to the embryo cortex. These transcripts decrease dramatically in abundance upon cellularisation at cycle 14. Levels of the transcript then rise in somatic cells (presumably resulting from zygotic transcription) as gastrulation starts and cell divisions resume.

The localisation of specific transcripts to particular regions of the developing Drosophila embryo seems to play a crucial part in embryonic development. In perhaps the best studied example, the localisation of the bicoid transcript to the anterior end of the embryo results in the formation of a morphogenic protein gradient (Driever and Nusslein-Volhard, 1988a,b). Sequences in the $3^{\prime}$ untranslated region of the bicoid mRNA are required for it to become correctly localised (Macdonald and Struhl, 1989). Little else is known, however, about the mechanisms that localise specific transcripts in the Drosophila embryo. In this paper, we investigate the mechanisms that are responsible for localising cyclin B transcripts both to the posterior pole and subsequently to the rest of the cortex.

\section{Materials and methods}

\section{Embryo collection, injection and fixation}

Embryos were collected and injected as described in Raff and Glover (1988). The drugs used in this study were injected at the following concentrations: $\alpha$-amanatin, $400 \mu \mathrm{g} \mathrm{ml}^{-1}$; colchicine, $1 \times 10^{-3} \mathrm{M}$; cytochalasin D, $250 \mu \mathrm{g} \mathrm{ml}^{-1}$; aphidicolin, $100 \mu \mathrm{g} \mathrm{ml}^{-1}$. Embryos were then fixed in 1:1 mixture of $4 \%$ paraformaldehyde in PBS (PP)/heptane. Embryos that were not injected were fixed directly in this mixture. The aqueous phase was removed, and the embryos were devitellinised by the addition of an equal volume of methanol followed by vigorous shaking for $30 \mathrm{~s}$ (Mitchison and Sedat, 1983). The embryos were rehydrated in a methanol/PP series $(7: 3,1: 1$, $3: 7-5 \mathrm{~min}$ each) and then postixed in PP for $20 \mathrm{~min}$. If the embryos were to be stored, they were dehydrated in an ethanol series and stored at $-20^{\circ} \mathrm{C}$ in $70 \%$ ethanol.

\section{Preparation of ${ }^{35} S$-RNA probes}

All probes were made from plasmid constructs containing cDNAs inserted between T3- and T7-RNA polymerase promoters (see Constructs below). The plasmids were linearised with a suitable restriction enzyme. This reaction was then treated with $200 \mu \mathrm{g} \mathrm{ml}^{-1}$ proteinase $\mathrm{K}$ (Sigma) at $37^{\circ} \mathrm{C}$ for $30 \mathrm{~min}$, then phenol extracted, chloroform extracted, and the DNA ethanol precipitated using standard techniques (Maniatis et al. 1982). RNA probes were prepared exactly as described in the Stratagene RNA Transcription kit (no. 200 341 ), using ${ }^{35} \mathrm{~S}$-UTP ( $>800 \mathrm{mCi} \mathrm{mmol}^{-1}$, Amersham), and either T7- or T3-RNA polymerase, depending on the sense of the probe required. The reaction was left at $37^{\circ} \mathrm{C}$ for $30-40 \mathrm{~min}$ and terminated by the addition of $1 / 10$ volume of $10 \times$ MS ( $10 \mathrm{~mm}$ Tris $\left.\mathrm{pH} 7.5,10 \mathrm{~mm} \mathrm{MgCl}_{2}, 50 \mathrm{~mm} \mathrm{NaCl}\right)$. The reaction was treated with $1 \mu \mathrm{l}$ of RNAase-free DNAase $\left(120 \mathrm{mg} \mathrm{ml}^{-1}, \mathrm{BRL}\right)$ for $7 \mathrm{~min}$ at $37^{\circ} \mathrm{C}$, then a $1 \mu \mathrm{l}$ aliquot was TCA precipitated and counted in Aquasol on a scintillation counter to determine the percentage incorporation. $30 \mu \mathrm{l}$ of tRNA $\left(10 \mathrm{mg} \mathrm{ml}^{-1}\right.$, phenol extracted, ethanol precipitated, and resuspended in DEPC-treated water) was added to the reaction, and the probe was phenol extracted, chloroform extracted and ethanol precipitated by adding an equal volume of $4 \mathrm{M}$ ammonium acetate and 2.5 volumes of ethanol. The probe was resuspended in $50 \%$ formamide (de-ionised, Rose), at between 0.5 and $2.5 \times 10^{6} \mathrm{cts} \mathrm{min}^{-1} \mu \mathrm{I}^{-1}$ and stored at $-20^{\circ} \mathrm{C}$ until used.

\section{Embryo sectioning and hybridisation to ${ }^{35} S-R N A$ probes}

The sectioning of embryos and the hybridisation of RNA probes to embryo sections was carried out as described by Ingham et al. 1985.

\section{Constructs}

The following constructs have been used in this study: pKScyc 1.7 , a $1.8 \mathrm{~kb}$ cDNA containing the $3^{\prime}$ end of the cyclin $\mathrm{B}$ mRNA in Bluescript pKS (Stratagene); pKScyc 1.2, a $1.4 \mathrm{~kb}$ cDNA encoding almost the entire coding region of the cyclin A gene in Bluescript pKS; NBA1, a $3.4 \mathrm{~kb}$ cDNA encoding the $3^{\prime}$ end of the lodestar mRNA (C. Girdham, personal communication); $10 \mathrm{a} 2$, a $2.1 \mathrm{~kb}$ cDNA containing the entire coding region of the polo gene (S. Llamazares, personal communication). These last two cDNAs were in the pNB40 vector (Brown and Kafatos, 1988).

\section{Preparation of digoxygenin probes for whole mount} in situ hybridisation

Appropriate restriction fragments from each of the above constructs were isolated. Digoxygenin probes were made with these fragments using a BCL kit (no. 1093 657). The reaction is essentially an oligolabelling reaction (Feinberg and Vogelstein, 1983, and addendum, 1984) and was carried out exactly as described in the BCL kit.

\section{Whole-mount hybridisation of embryos to digoxygenin probes}

The methods we used were exactly those described by Tautz and Pfeiffe (1989), except that embryos were fixed as described above. After hybridisation and staining, the embryos were incubated in Hoechst $33258\left(1 \mu \mathrm{g} \mathrm{ml}^{-1}\right)$ for $20 \mathrm{~min}$, and then mounted in mounting medium (85\% glycerol, $2.5 \%$-propylgallate). Photography was performed as described in Raff and Glover (1988).

\section{Antibody staining}

To reveal the distribution of the vasa protein, embryos were fixed and stained essentially as described by Lasko and Ashburner (1990), using a polyclonal serum raised against the vasa protein, except that we used second antibodies directly conjugated to horse-radish peroxidase (Jackson). 


\section{Fly stocks}

The following mutant stocks have been used in this study: $b \mathrm{pr}$ stau $^{\mathrm{C} 8} / \mathrm{CyO} ; b$ pr stau ${ }^{\mathrm{G} 2} / \mathrm{CyO} ; b$ pr cn sca tud $\mathrm{d}^{\mathrm{B} 36} / \mathrm{CyO}$;

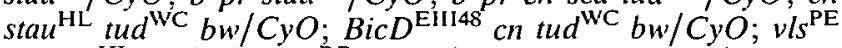
cn stau ${ }^{\mathrm{HL}} b w / C y O ; v l s^{\mathrm{RB}} \mathrm{cn} b w / C y O ; D f(2 L) T W 2 / C y O ; t h$ st in ri roe $p^{\mathrm{p}}$ osk $\mathrm{k}^{301} / T M 3$; th st in ri roe $p^{\mathrm{p}}$ osk ${ }^{166} / T M 3$; vasa ${ }^{\mathrm{PD} 23} \mathrm{cn}$ bw/TM3; capu ${ }^{\mathrm{RK} 12}$ bw cn sp/CyO; spir ${ }^{\mathrm{RP} 18} \mathrm{cn}$ bw/CyO; st nos ${ }^{53}$ e/TM3; st nos ${ }^{\mathrm{L} 7}$ e/TM3; st pum ${ }^{680} / T_{M} 3 ; b$ $B i c D^{\mathrm{IIIE} 48} \mathrm{cn} / \mathrm{CyO}$.

\section{Results}

The pattern of cyclin $B$ mRNA distribution does not depend on zygotic transcription

In the early Drosophila embryo, there is very little transcription during the first 9-10 nuclear cycles. After this, transcription levels gradually increase at successive nuclear cycles (Edgar et al. 1986; Edgar and Schubiger, 1986), and at nuclear cycle 14, the embryo requires zygotic transcription to drive cellularisation and further embryonic development. Although embryos apparently develop normally in the absence of zygotic transcription until cycle 14 (Edgar et al. 1986; Wieschaus and Sweeton, 1988; Merrill et al. 1988), there is evidence that the zygotic transcription of at least one gene may be required as early as nuclear cycle 6 (Karr et al. 1989).

To test whether de novo transcription played any part in generating the pattern of cyclin $B$ mRNA distribution, we injected the transcription inhibitor $\alpha$-amanatin $\left(400 \mu \mathrm{g} \mathrm{ml}^{-1}\right)$ into embryos at nuclear cycle 1-3 and allowed them to develop for varying lengths of time before fixation. Even though it has previously been shown that this concentration of $\alpha$-amanatin effectively inhibits RNA polymerase II-dependent transcription (Edgar et al. 1986), we found that it had little effect on the early nuclear cycles of the embryo. At nuclear cycle 14, however, cellularisation and gastrulation were completely inhibited, demonstrating that the drug was inhibiting the zygotic transcription required for these processes to occur. When $\alpha$-amanatin-injected embryos were fixed, sectioned and hybridised to cyclin B antisense RNA probes, the pattern of mRNA distribution (not shown) was found to be the same as in untreated embryos (Whitfield et al. 1989 and below).

\section{Cyclin $B$ mRNA is localised around nuclei and comigrates with them to the embryo cortex}

To look more closely at the cortical accumulation of the cyclin B transcripts observed previously (Whitfield et al. 1989), we hybridised embryo sections to antisense cyclin B RNA probes (Fig. 1), but, instead of staining the sections with Giemsa stain, we stained them with the DNA-binding fluorochrome Hoechst 33258 (lefthand panels). This figure shows syncytial embryos at progressively later stages of development (panels $A-D)$. We found that the cyclin B mRNA (right-hand panels) was concentrated around nuclei which are found in the interior of the early embryo (Fig. 1A). As the nuclei migrated to the cortex, they carried large amounts of the transcript with them (Fig. 1B). In this way, the transcript was progressively cleared from the interior of the embryo and accumulated at the embryo cortex (Fig. 1C,D).

Because each nucleus in the syncytial Drosophila embryo is surrounded by a yolk-excluding region (Foe and Alberts, 1983), it was possible that all maternally contributed transcripts would preferentially accumulate in this region. To test this possibility, we performed a series of hybridisations to early embryo sections with three probes from genes whose transcripts are known to be maternally contributed to the early embryo: cyclin A, polo (S. Llamazares, personal communication) and lodestar (C. Girdham, personal communication). In each case, the transcripts were found to be evenly distributed in the early embryo, and then appeared to be progressively excluded from the developing inner yolk mass, leading to an accumulation in a broad band of cytoplasm below the cortex. This is illustrated for cyclin A transcripts in Fig. 2, which displays a series of syncytial embryos at comparable developmental stages to those shown in the previous figure. Although all of these transcripts were concentrated around nuclei to some extent, this localisation was much less dramatic than in the case of the cyclin B transcript (compare Fig. 2A,B with Fig. 1A,B), and the subsequent relocalisation of these transcripts to the embryo cortex was correspondingly less striking (compare Fig. 2C,D with Fig. 1C,D). Thus, the perinuclear localisation and cortical migration of the cyclin $B$ transcript are not features common to all maternally derived transcripts.

\section{Microtubules are involved in localising the cyclin $B$ transcript around nuclei}

As the migration of nuclei to the cortex of the Drosophila embryo is dependent upon functional microtubules (Zalokar and Erk, 1976; Raff and Glover, 1989), we investigated the effects of colchicine, an inhibitor of microtubule polymerisation, upon the nuclear association of the cyclin B transcripts and their migration to the cortex. We found that both the perinuclear localisation and cortical migration of the transcripts were blocked by colchicine (Fig. 3). Cytochalasin D, an inhibitor of microfilament polymerisation, had no effect on these processes (not shown). Neither drug affected the posterior localisation of the transcript. In order to examine the relationship between the distribution of the transcript and the microtubules in the embryo, we used the recently developed technique of in situ hybridisation on wholemount preparations of embryos (Tautz and Pfeiffe, 1989). At nuclear cycle 10, when the nuclei are at the cortex, much of the cyclin B RNA was seen to be concentrated in the regions around nuclei that are rich in microtubules (Fig. 4). This is most obvious at metaphase, when transcripts are clearly concentrated in a bipolar fashion around the metaphase chromosomes (Fig. 4B). When we examined the distribution of cyclin $A$, polo and lodestar transcripts with this technique, there was no obvious accumulation of these transcripts in the regions around nuclei that are rich in microtubules (not shown). 

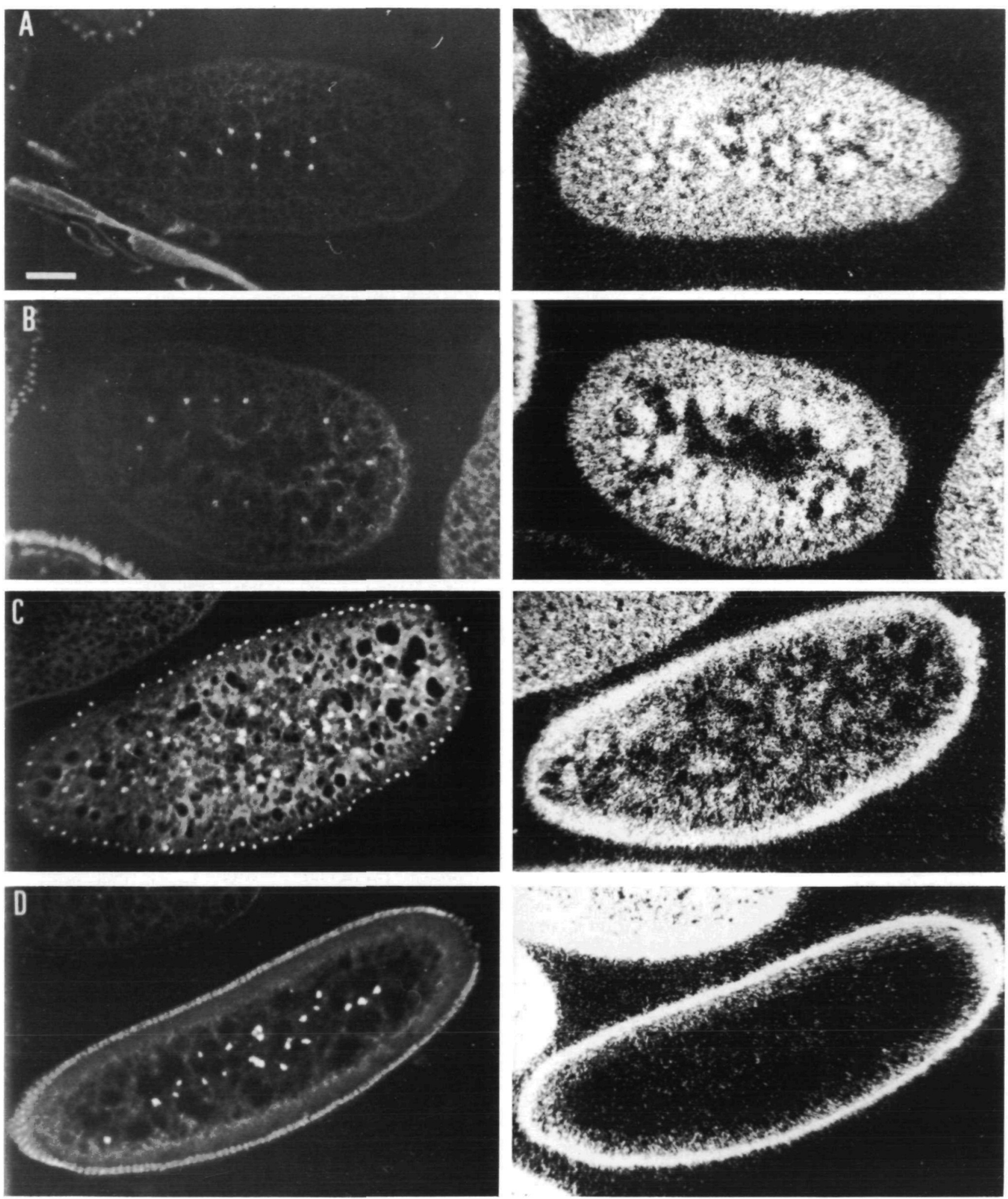

Fig. 1. The distribution of cyclin B transcripts during early embryo development. Embryo sections were hybridised to an antisense RNA probe synthesised from a cyclin B cDNA. The embryos were at nuclear cycle 5-6 (A), 7-8 (B), 11-12 (C) and 14 (D). The right-hand panels show Hoechst fluorescence, revealing the distribution of nuclei, and the left-hand panels are dark-field images. The transcript is concentrated around the nuclei (A), and migrates to the cortex with the migrating nuclei $(B)$, generating the cortical localisation of the transcript $(C, D)$. Note how at cycle 14 the transcripts are very tightly localised to the cortex. Bar $=50 \mu \mathrm{m}$. 

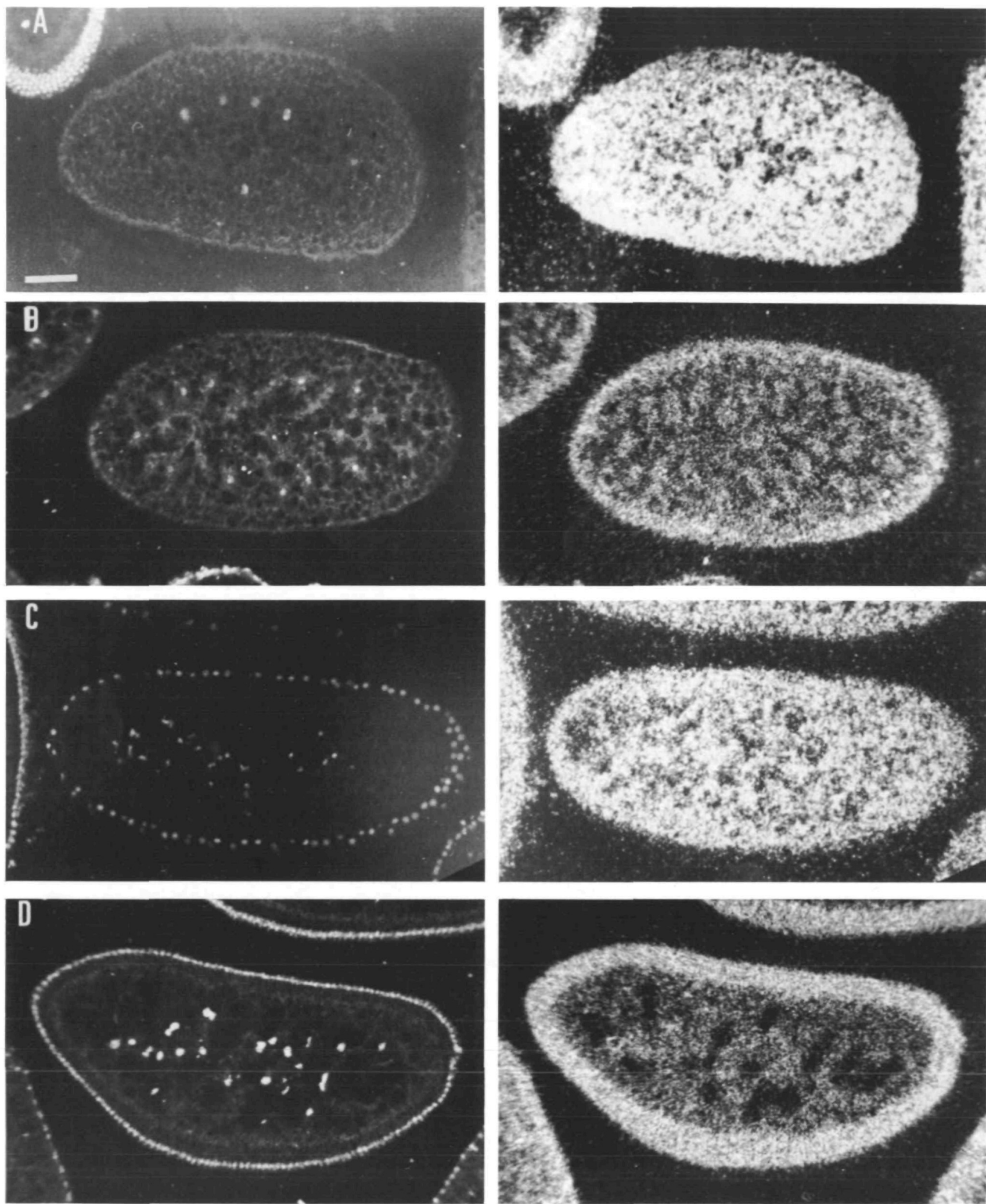

Fig. 2. The distribution of cyclin A transcripts during early embryo development. Embryo sections were hybridised to an antisense RNA probe synthesised from a cyclin A cDNA. The embryos were at nuclear cycle 5-6 (A), 7-8 (B), 12 (C) and 14 (D). The right-hand panels show Hoechst fluorescence, revealing the distribution of nuclei, and the left-hand panels are dark-field images. The nuclear localisation and cortical accumulation of the transcript are much less obvious than that observed for cyclin B. Note how at cycle 14 the transcripts are localised to a broad band of cortical cytoplasm whereas the cyclin B transcripts (Fig. 1D) are very tightly localised to the cortex. Bar $=50 \mu \mathrm{m}$. 

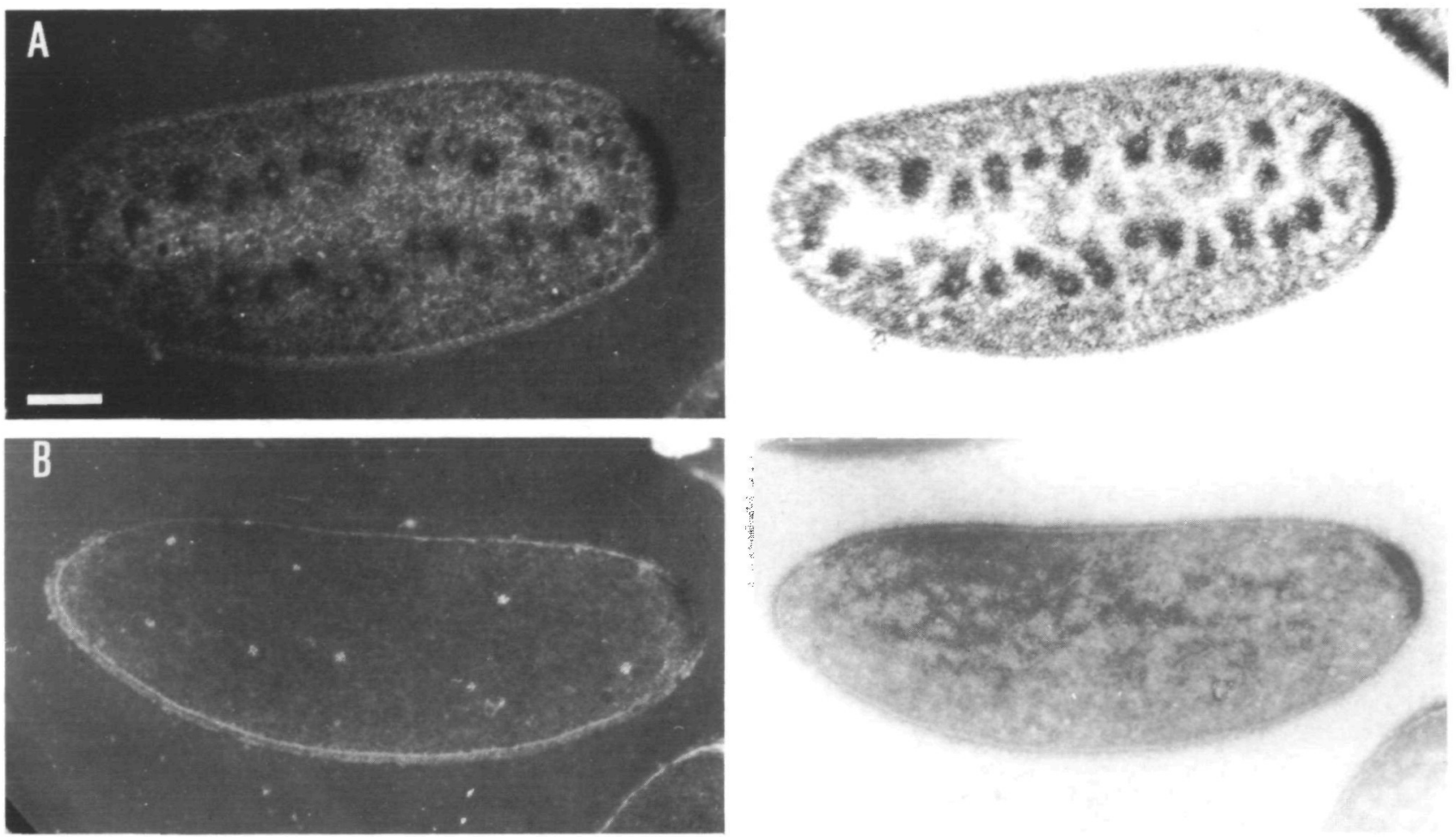

Fig. 3. The nuclear localisation and cortical accumulation of the cyclin B transcript are blocked by colchicine. Left-hand panels show Hoechst fluoresence, right-hand panels show bright-field images. (A) An untreated embryo at cycle 7-8, (B) an embryo injected with colchicine at nuclear cycle 6-8 that was allowed to develop for 40 min after injection before fixation. These sections were over-exposed as this makes the perinuclear localisation of the transcript very easy to observe. The colchicine-injected embryo has no hint of a perinuclear localisation, and the transcripts, like the nuclei, have not migrated to the cortex. $\mathrm{Bar}=50 \mu \mathrm{m}$.

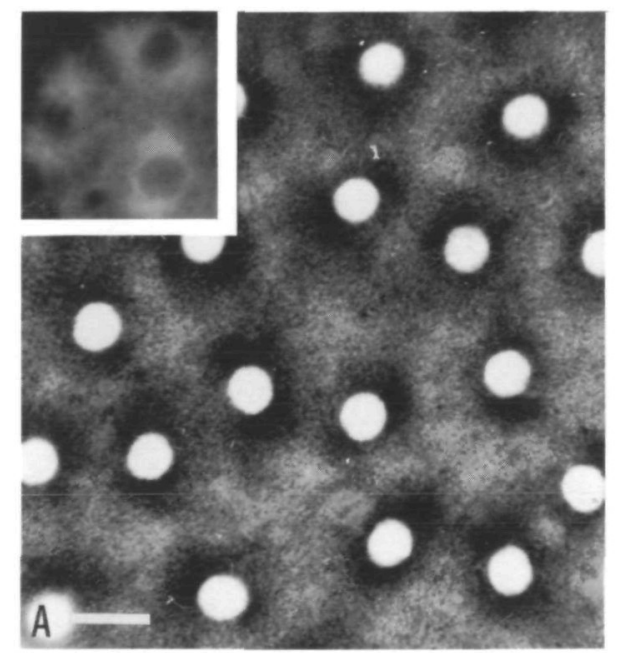

INTERPHASE

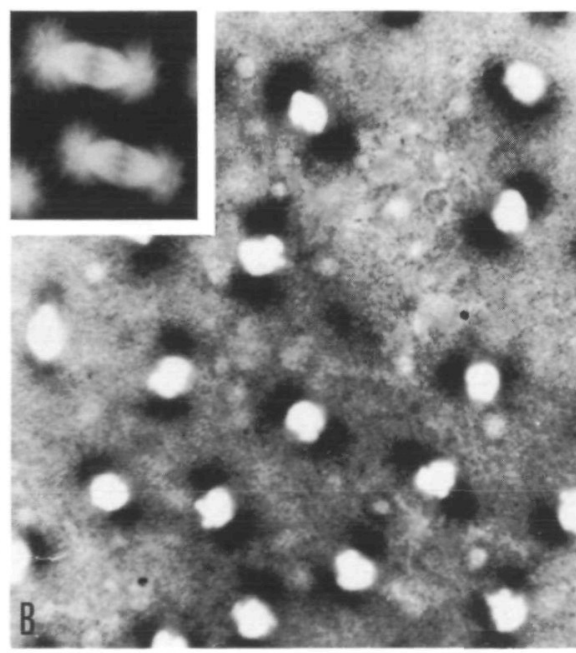

METAPHASE

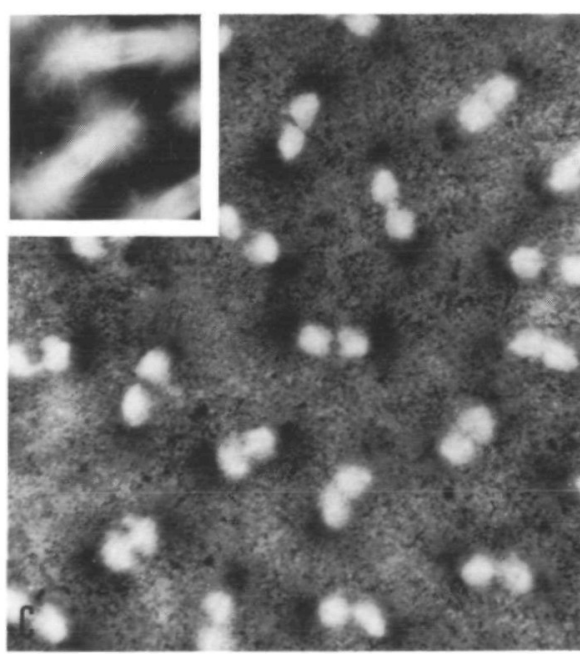

ANAPHASE

Fig. 4. Cyclin B transcripts are concentrated around the regions of nuclei that are rich in microtubules. The Figure shows three fields taken from different embryos at different mitotic phases of nuclear cycle 10: (A) interphase, (B) metaphase, (C) anaphase. These embryos were fixed and hybridised with a digoxygenin DNA probe (see Materials and methods). The figures show both the bright field images, revealing the distribution of the transcripts, and the fluorescent images, of the nuclei, superimposed. For technical reasons it was not possible to stain these embryos with antibodies to reveal the distribution of microtubules. The insets, however, show the microtubule structures typically found at these stages of the nuclear cycle. At interphase, the transcript is accumulated around nuclei, and in many cases a slight bipolarity in the distribution of the signal is apparent because the centrosomes have divided and migrated around the nuclei; this bipolarity becomes even more marked at metaphase and anaphase. Bar $=10 \mu \mathrm{m}$. 
A

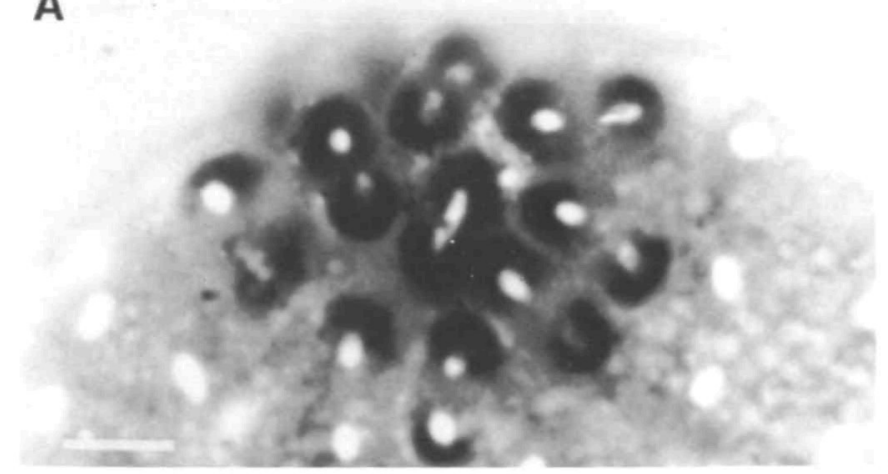

B

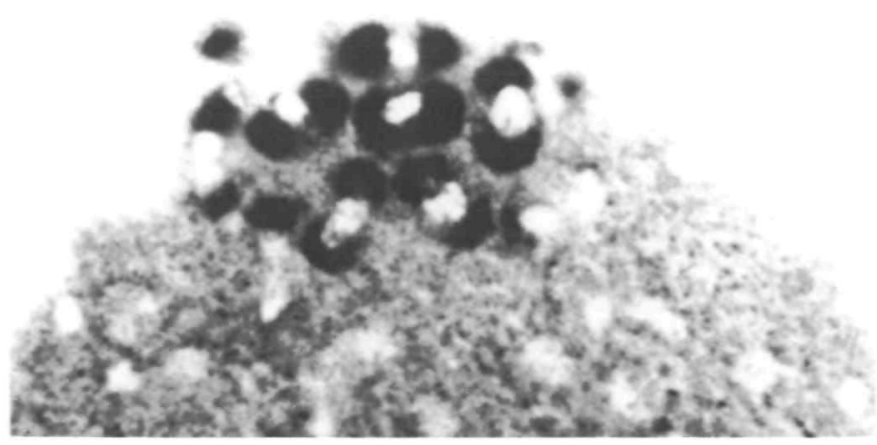

Fig. 5. Cyclin B transcripts and polar granules are both concentrated around spindles at the posterior pole. The figure shows the distribution of the vasa protein (A) and cyclin B transcripts (B) at the posterior pole of embryos initiating pole bud formation. Bar $=10 \mu \mathrm{m}$.

Cyclin B transcripts are localised to the posterior pole in early embryos and unfertilised eggs

It was shown previously that cyclin B transcripts become concentrated to the posterior pole of Drosophila embryos at some time before pole buds are formed (Whitfield et al. 1989). When we looked at the distribution of cyclin B transcripts in whole-mount embryos, we found that they were concentrated at the posterior pole in even the earliest embryos with only one or two nuclei, and the same distribution was also apparent in unfertilised eggs (not shown). It seems, therefore, that cyclin B transcripts become concentrated to the posterior pole during oogenesis, rather than during embryogenesis as previously reported (Whitfield et al. 1989). Ongoing studies indicate that the localisation of cyclin B transcripts during oogenesis is a complex process. This reflects the need to establish the two major patterns of maternal transcript deposition in the egg. In this present communication, we therefore restrict our analysis to the factors that influence the final patterns of RNA distribution.

The distribution of cyclin $B$ transcripts at the posterior pole was strikingly similar to the distribution of polar granules, organelles found exclusively in the posterior cytoplasm. Polar granules develop late in oogenesis, become incorporated into the pole cells and are believed to be involved in germ cell determination. Recently, the protein encoded by the vasa gene (Lasko and Ashburner, 1988; Hay et al. 1988b) was found by immuno-electron microscopy to be a component of polar granules (Hay et al. 1988a), providing a convenient way of visualising these organelles in the embryo. Both the vasa protein (Hay et al. 1988a) and the cyclin B transcripts at the posterior pole were initially homogeneously distributed within a tight cap at the posterior cortex. As the nuclei arrive at the posterior pole, the vasa protein and the cyclin B transcript become highly concentrated around the nuclei. At higher magnifications, the vasa protein and cyclin B transcript staining around the nuclei at the posterior pole has a granular appearance (not shown, but see also Lehner and O'Farrell (1990) for an example of this distribution). As the microtubules become reorganised into a mitotic spindle, virtually all of the vasa protein and the cyclin B transcript become concentrated in the regions expected to be occupied by microtubules (Fig. 5). Indeed it has previously been shown that polar granules accumulate around centrioles (Rabinowitz, 1941; Counce, 1963; Mahowald, 1968). This distribution appears to differ from that seen for the cyclin B transcripts around the rest of the embryo cortex, where not all of the transcripts are concentrated around microtubules (Fig. 6).

A similar distribution of cyclin B transcripts at the posterior pole is also seen in embryos injected with the DNA synthesis inhibitor aphidicolin (Ikegami et al. 1978). When aphidicolin is injected at nuclear cycle $7-8$, the centrosomes can often migrate to the cortex without nuclei (Raff and Glover, 1989). At the posterior pole, centrosomes alone can initiate pole bud formation in the absence of a nucleus. These buds are only initiated when a centrosome reaches the posterior pole, and each bud always contains a centrosome. In such embryos, virtually all of the detectable signal from the cyclin B transcript at the posterior pole appears concentrated in the regions around centrosomes about which the pole buds are forming (Fig. 7A). This same pattern was found when such embryos were stained to reveal the distribution of the vasa protein (not shown). We found, however, by examining the distribution of cyclin B transcripts in sections of such aphidicolininjected embryos, that the majority of the RNA in the rest of the embryo did not migrate to the cortex with the centrosomes alone (not shown - see Discussion).

The posterior localisation of the cyclin B transcript is disrupted in mutant embryos that fail to form pole cells

The observations described above raised the possibility that the cyclin B transcripts at the posterior pole are associated with polar granules. To test this possibility, we looked at the localisation of the transcript in embryos that have no polar granules. Genetic studies have identified seven genes that play a part in polar 
granule formation: vasa, oskar, valois, tudor, staufen, cappuccino and spire. Embryos from females homozygous for any one of these mutations (which we shall call VAS, OSK, VAL, TUD, STAU, CAPU, and SPIR embryos respectively) lay embryos that have no polar granules, fail to form pole cells, and usually have a variety of other defects associated with the absence of abdominal structures (Boswell and Mahowald, 1985; Schupbach and Wieschaus, 1986; Lehmann and Nusslein-Volhard, 1986; Manseau and Schupbach, 1989).
A

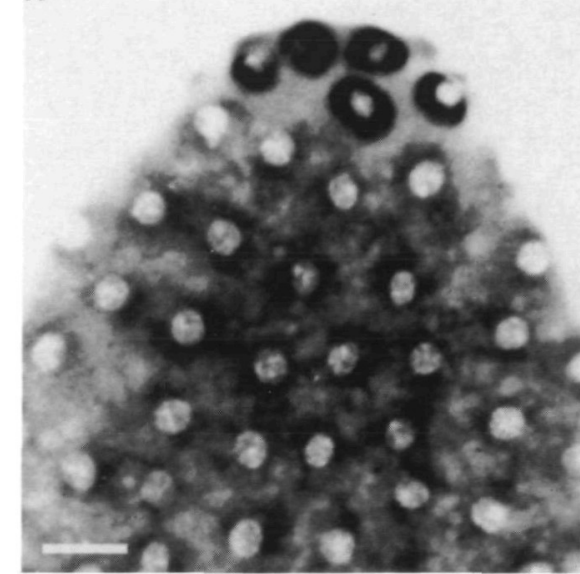

INTERPHASE
B

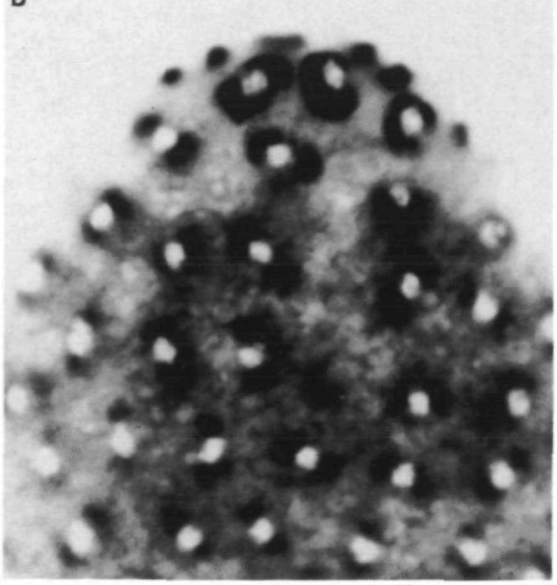

METAPHASE

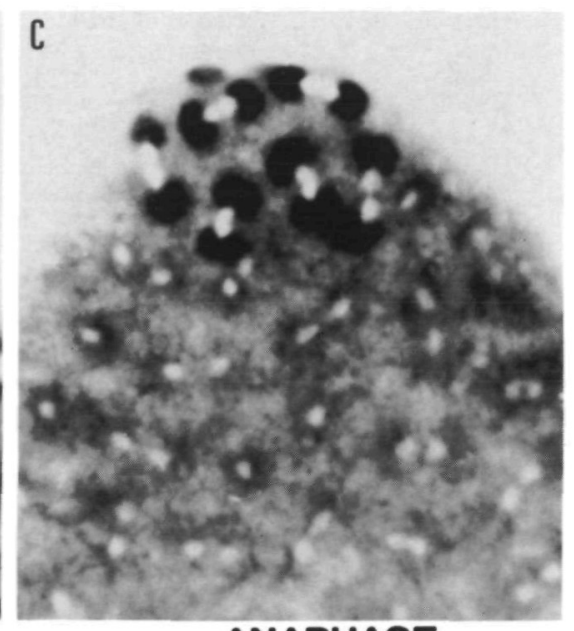

ANAPHASE

Fig. 6. The cyclin.B transcripts localised at the posterior pole appear to be more dramatically concentrated around microtubules than the transcripts around the rest of the embryo cortex. The Figure shows the posterior region of three different embryos at different mitotic phases of nuclear cycle 9-10: (A) interphase, (B) metaphase, (C) anaphase. As in Fig. 3, the figures show both the bright-field images, revealing the distribution of the transcripts, and the fluorescent images, of the nuclei, superimposed. Virtually all of the cyclin B transcript at the posterior pole is localised around the microtubules surrounding the polar nuclei. At the rest of the cortex, there is a much higher background of transcripts that are not concentrated so dramatically around the nuclei. Bar $=20 \mu \mathrm{m}$.
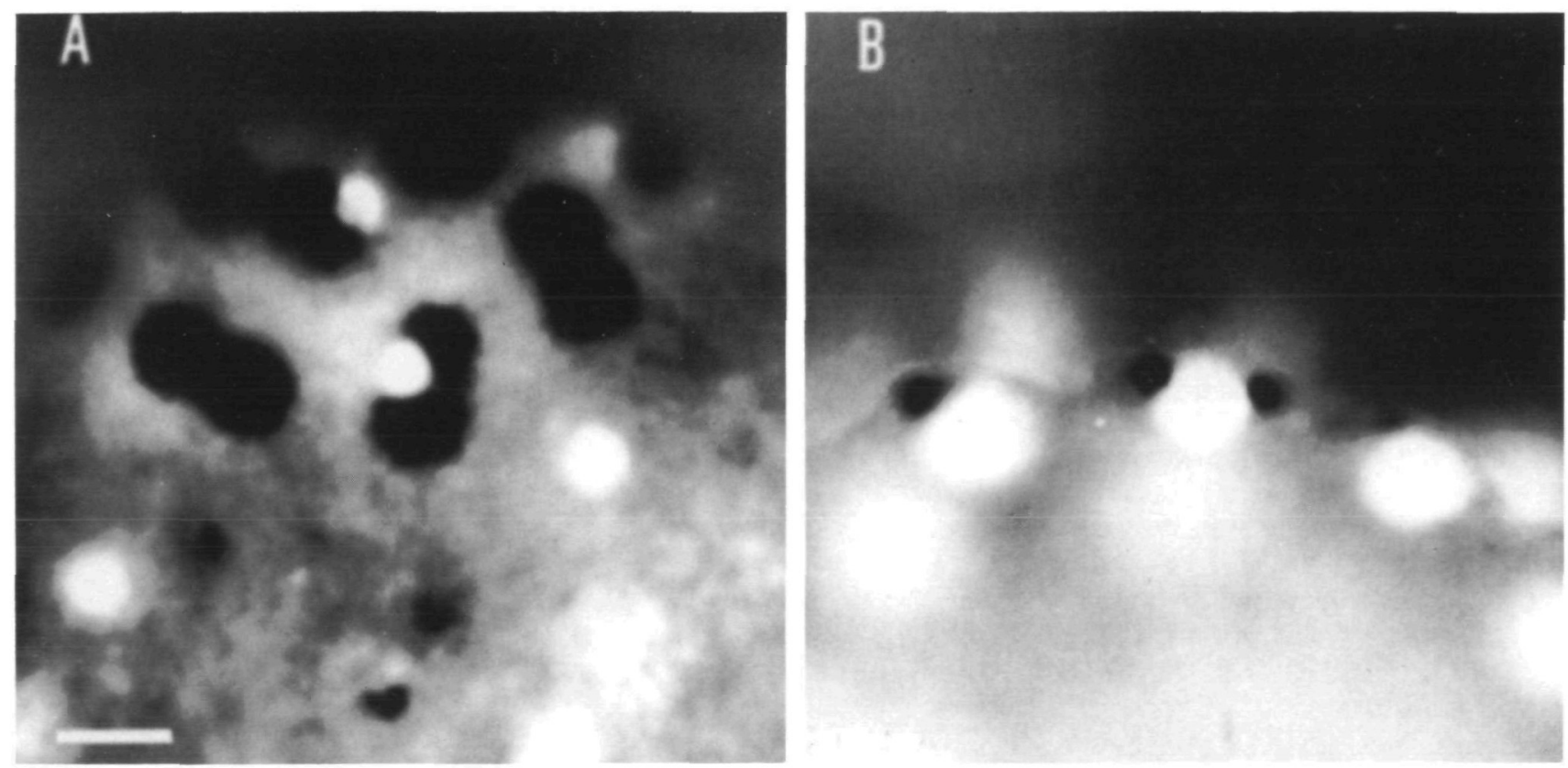

Fig. 7. The distribution of cyclin B transcripts at the posterior pole of aphidicolin-injected embryos and OSK embryos. The embryo in A was injected with aphidicolin at nuclear cycle 7-8 and observed to initiate pole bud formation under the light microscope. The embryo was then fixed and hybridised with a cyclin B digoxygenin DNA probe. Virtually all of the signal from the cyclin B transcript is accumulated in the anucleate pole buds that are organised by centrosomes. The embryo in B was laid by a female homozygous for the mutation $o s k^{301}$ at $18^{\circ} \mathrm{C}$. In such embryos, there is much less cyclin B mRNA concentrated at the posterior cortex by the time the nuclei arrive there. These transcripts, however, are still highly concentrated around the centrosomes. $\operatorname{Bar}(\mathrm{A})=10 \mu \mathrm{m} . \mathrm{Bar}(\mathrm{B})=5 \mu \mathrm{m}$. 
Table 1. The localisation of cyclin B transcripts and the vasa protein in mutant embryos that lack polar granules

\begin{tabular}{|c|c|c|c|c|}
\hline & mutant alleles & $\begin{array}{c}\text { cyclin B } \\
\text { RNA localised }\end{array}$ & $\begin{array}{l}\text { vasa protein } \\
\text { localised }\end{array}$ & $\begin{array}{c}\text { polar } \\
\text { granules }\end{array}$ \\
\hline capu & RK12/RK12 & - & - & - \\
\hline spir & RP18/RP18 & - & - & - \\
\hline stau & $\mathrm{C} 8 / \mathrm{G} 2$ & - & - & - \\
\hline vasa & PD23/PD23 & - & - & - \\
\hline osk & $\begin{array}{l}\text { 166/Df } \\
301 / 301\left(29^{\circ} \mathrm{C}\right) \\
301 / 301\left(18^{\circ} \mathrm{C}\right)\end{array}$ & $\begin{array}{l}- \\
\overline{+}\end{array}$ & $\begin{array}{l}- \\
- \\
-\end{array}$ & $\begin{array}{l}- \\
- \\
-\end{array}$ \\
\hline tud & $\begin{array}{l}\mathrm{WC} / \mathrm{WC} \\
\mathrm{WC} / \mathrm{B} 36\end{array}$ & $\begin{array}{l}+ \\
+\end{array}$ & $\begin{array}{l}+ \\
+\end{array}$ & $\begin{array}{l}- \\
-\end{array}$ \\
\hline vls & $\begin{array}{l}\mathrm{PE} / \mathrm{Df} \\
\mathrm{RB} / \mathrm{RB}\end{array}$ & $\begin{array}{l}+ \\
+\end{array}$ & $\begin{array}{l}+ \\
+\end{array}$ & $\begin{array}{l}- \\
-\end{array}$ \\
\hline nos & $\mathrm{L} 7 / 53$ & + & + & + \\
\hline pum & $680 / 680$ & + & + & + \\
\hline \multicolumn{5}{|c|}{$\begin{array}{l}\text { A }(-) \text { sign indicates that the cyclin B transcript or the vasa protein was not concentrated at the posterior pole. A }(+) \text { sign indicates that } \\
\text { either the cyclin B transcripts or the vasa protein were initially localised to the posterior pole. In all of these cases, however, the } \\
\text { concentration at the posterior pole was always weaker than that observed in wild-type embryos, and it faded as development proceeded. } \\
\text { In TUD embryos both the cyclin B transcript and the vasa protein were no longer concentrated at the posterior pole by nuclear cycle } 5-10 \\
\text { (variable from embryo to embryo). In VLS and OSK }{ }^{301}\left(\text { at } 18^{\circ} \mathrm{C}\right) \text { embryos, the cyclin B transcript was often still localised to the posterior } \\
\text { pole of cycle } 10-14 \text { embryos, although no pole cells were formed. In VLS embryos the concentration of vasa protein at the posterior pole } \\
\text { had usually faded by this stage, and the protein was not localised to the posterior pole of OSK }{ }^{301} \text { embryos at all. }\end{array}$} \\
\hline
\end{tabular}

CAPU and SPIR embryos also have defects associated with dorsal/ventral pattern formation (Manseau and Schupbach, 1989).

The distribution of the vasa protein in these mutants has recently been reported (Lasko and Ashburner, 1990). We repeated these experiments, and in addition looked at the distribution of cyclin B transcripts (Fig. 8 and Table 1). We confirmed that the posterior localisation of the vasa protein was completely abolished in CAPU, SPIR, STAU and VAS embryos, and showed that this was also true for cyclin B transcripts (see Fig. $8 \mathrm{~B}$ for an example). Both the vasa protein and the cyclin B transcripts were, however, localised to the posterior pole of VLS and TUD embryos, although this localisation was less striking than that seen in wild-type embryos, and it rapidly faded as development proceeded (for an example see Fig. 8C, and for details see Table 1). In weak $v / s$ alleles, the cyclin B transcripts were still concentrated at the posterior pole in some embryos at cycle 13-14 (see Fig. 8D), even though the vasa protein could not be detected there after cycle 5-10. In the strongest allelic combination of osk available, both the vasa protein and the cyclin B transcript were absent from the posterior pole. The same was true of the temperature-sensitive allele $o s k^{301}$ at $29^{\circ} \mathrm{C}$, where the phenotype is strongest; at $18^{\circ} \mathrm{C}$, however, cyclin B transcripts were localised to the posterior pole in these embryos while the vasa protein was not. As in the other mutants where the cyclin B transcripts were concentrated at the posterior pole, this localisation was less striking than in wild-type embryos and it was lost as development proceeded. A small amount of the transcript was still concentrated at the posterior pole at cycle 10-14 in some of these OSK embryos. In such embryos (and in VLS embryos where the posteriorly localised transcript was still apparent at cycle 10), the distribution of transcripts was consistent with them being localised around centrosomes (Fig. 7B).

Embryos laid by females homozygous for the mutations nanos or pumilio have polar granules, form pole cells, but have a variety of abdominal defects similar to those found in the mutants described above. We found that the distributions of both the vasa protein and the cyclin B transcript in these embryos were indistinguishable from those seen in wild-type embryos prior to cellularisation. We also looked at the distribution of the cyclin B transcript in embryos laid by females heterozygous for the dominant mutation Bicaudal D ${ }^{\text {IIE48 }}$ (Mohler and Wieschaus, 1986). In our hands, approximately $8 \%$ of these embryos developed into embryos with a duplicated posterior pole and abdominal structures at the anterior end. These duplicated posterior poles, however, lack polar granules and do not form pole cells. In over 600 embryos screened, we did not observe a single embryo with cyclin B transcripts concentrated at the anterior pole. Together, these observations suggest that the posterior accumulation of the cyclin B transcripts is not required for the formation of abdominal structures.

\section{Discussion}

We have shown that maternally contributed cyclin B transcripts accumulate around nuclei at the earliest stages of Drosophila embryo development. As the nuclei migrate to the cortex, they take large amounts of the cyclin B transcript to the cortex with them, thereby clearing the transcript from the interior of the embryo. 
A

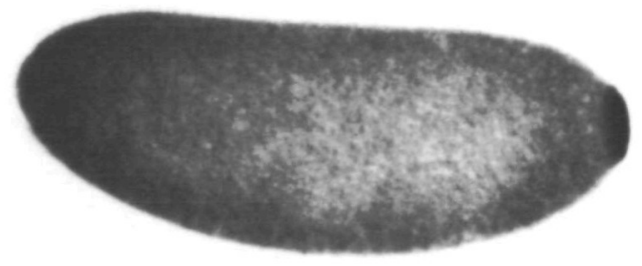

I

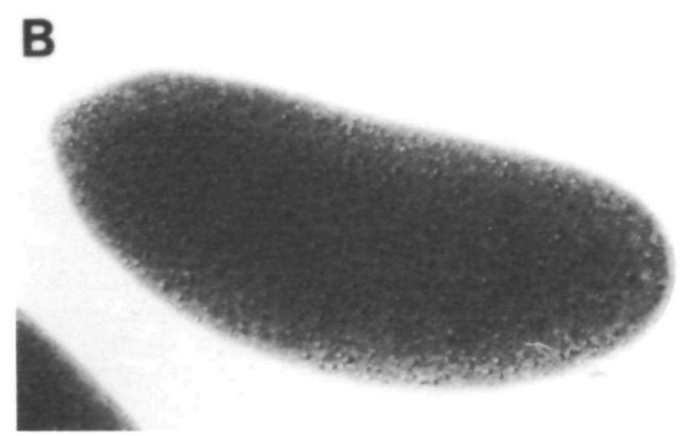

C

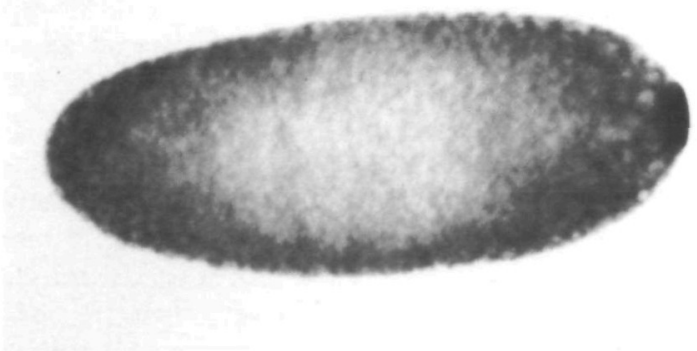

D

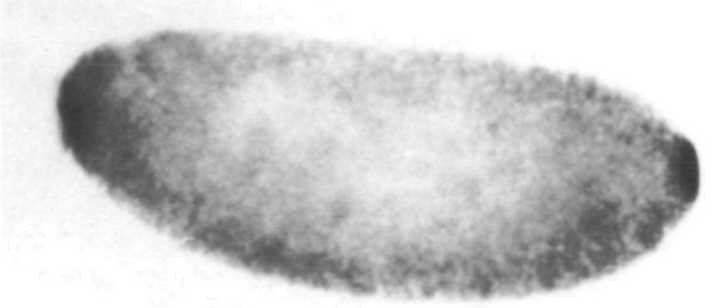

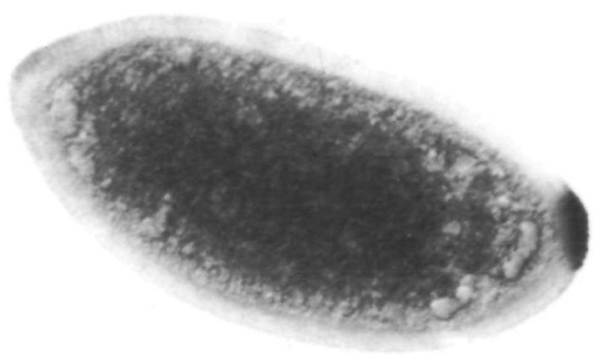
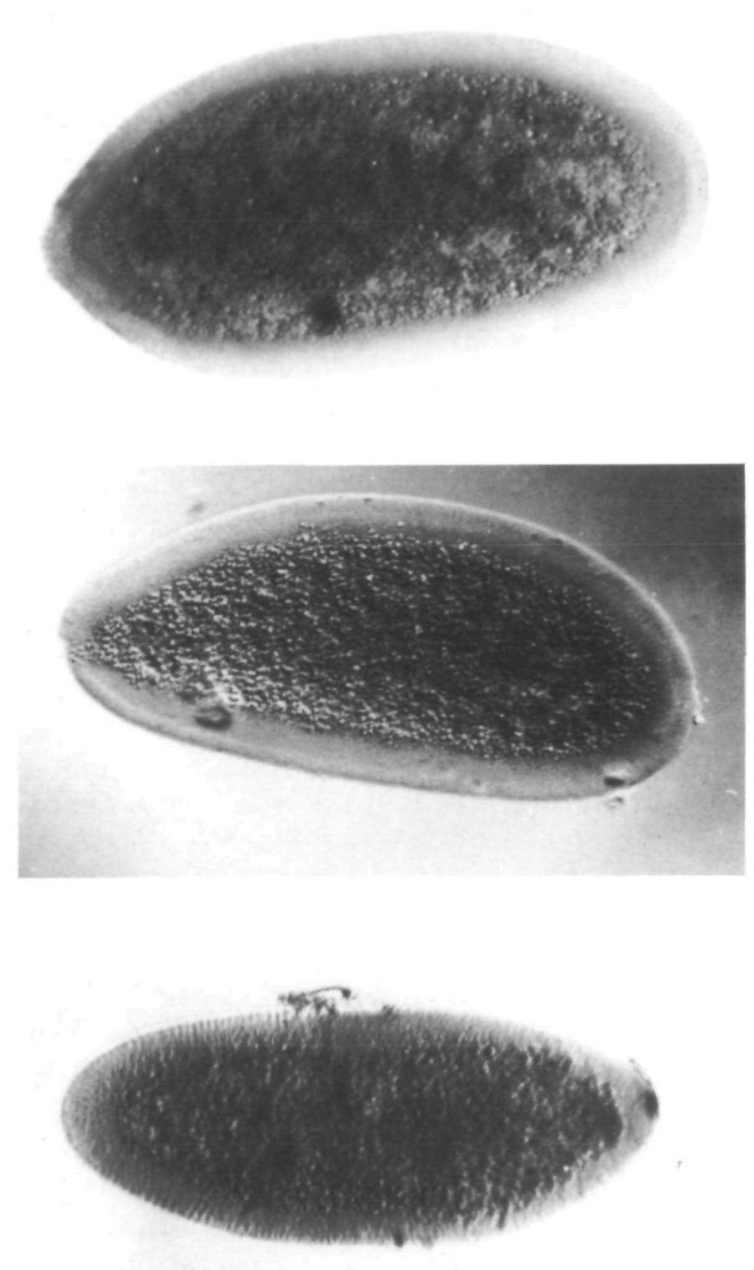

Fig. 8. The distribution of the cyclin B transcript in embryos that lack polar granules. The embryos were fixed, hybridised with a cyclin B digoxygenin DNA probe and stained to visualise the cyclin B transcript. In order to stage the embryos, they were also stained with Hoechst to reveal the distribution of the nuclei, although this is not shown. The left-hand panels show embryos between nuclear cycles $2-5$, the right-hand panels show embryos at cycle 14 . (A) Wild-type embryos. The cyclin B is concentrated at the posterior pole and becomes incorporated into pole cells. This staining pattern was also found for NOS and PUM embryos. (B) VASA embryos. No concentration of cyclin B transcripts is observed at the posterior pole. This staining pattern is also found for CAPU, SPIR, STAU and OSK (derived from both osk ${ }^{166} / D f$ females, and $o s k^{301} / o s k^{301}$ females with development at $29^{\circ} \mathrm{C}$ ). (C) TUD embryos. Cyclin B transcripts are initially concentrated at the posterioir pole, but this concentration fades as development proceeds. This pattern is also seen in VLS and OSK embryos (derived from osk ${ }^{301} / o s k^{301}$ females with development at $18^{\circ} \mathrm{C}$ ). (D) VLS embryos. In the cycle 14 embryo shown, the cyclin B transcript is still weakly concentrated at the posterior pole (note that no pole cells have formed). This pattern is only seen ocassionally in VLS $\left(v l s^{\mathrm{RB}} / v^{\mathrm{RB}}\right.$-derived) and OSK (osk $k^{301} / o s k^{301}$-derived) embryos. 
This process explains how the previously observed cortical accumulation of the transcript is generated. Colchicine, an inhibitor of microtubule polymerisation blocks the accumulation of the transcripts around nuclei, raising the possibility that the transcript might be associating with microtubules. Furthermore, we found that the transcript was concentrated in the regions around nuclei that are rich in microtubules. Taken together, these findings suggest that the cyclin B transcript associates either directly with microtubules or with components that are microtubule-associated.

Although it appears that cyclin transcripts associate with microtubules in some way, we found that the majority of the transcripts do not migrate to the cortex when aphidicolin is injected into embryos, thus allowing centrosomes to migrate to the cortex without nuclei. This result is perhaps not surprising. The extent to which microtubules break down when centrosomes dissociate from incompletely replicated chromatin is not clear. It is apparent, however, that the centrosomes do not take the bulk of the cytoplasm surrounding the nuclei with them to the cortex (J.W.R. unpublished observations). We presume that most of the transcripts remain localised in these remaining islands of cytoplasm. It is also possible that only microtubules associated with either nuclei or condensed chromosomes can, either directly or indirectly, bind cyclin B RNA.

We can only speculate about the possible functions the peri- nuclear localisation of the cyclin B transcript might have. The levels of cyclin A and cyclin B proteins detected with antibodies in whole mounts of Drosophila embryos do not appear to undergo dramatic variation during the first 13 cycles of nuclear division (Lehner and O'Farrell, 1989, 1990; Maldonado-Codina and Glover, unpublished data). This is in contrast to other organisms, where cyclin protein levels rise and fall in synchrony with the cell cycle in whole embryo extracts (Evans et al. 1983; Murray and Kirschner, 1989). This cycling pattern is, however, found in the Drosophila embryo after cycle 14 when the nuclei have cellularised (Lehner and O'Farrell, 1989, 1990; Whitfield et al. 1990). The apparent lack of cyclin protein cycles in syncytial Drosophila embryos is puzzling, especially in the light of experiments showing that the destruction of cyclin B protein is necessary for the exit from mitosis in amphibian cell extracts (Murray et al. 1989). It is possible that in the syncytial Drosophila embryo, either the activities of the cdc2-cyclin complexes are modulated only by post-translational modifications such as their state of phosphorylation, or the cyclin proteins only undergo cyclical degradation in a localised region around each nucleus rather than over the whole cytoplasm. Preliminary data indicate that cyclin B protein is concentrated in the same region of the syncytial embryo as is its mRNA (Maldonado-Codina and Glover, unpublished). This is consistent with evidence from a number of species that cdc 2 kinase is associated with the mitotic spindle (e.g. see Riabowol et al. 1989); that the kinase can regulate microtubule dynamics in vitro (Verde et al. 1990); and with the association of the $S$. pombe cyclin, the $c d c 13^{+}$gene product, with microtubules as originally postulated by Booher and Beach (1988) and recently demonstrated in immunofluorescence studies by J. Hyams (personal communication). Thus the association of cyclin $B$ transcripts with microtubules could act to concentrate the transcript where the protein is required. Alternatively, the mRNA could be 'dragged' into this region by localisation signals present on nascent cyclin $B$ peptides on polysomes.

We found that cyclin B transcripts are concentrated at the posterior pole of the earliest embryos and in unfertilised eggs. This was missed in earlier observations (Whitfield et al. 1989) which were made using embryo sections rather than whole-mount preparations. The posterior localisation of the transcript is not disrupted by inhibitors of microtubule or microfilament polymerisation (although these can only be injected after the transcript has initially become localised to the posterior pole), suggesting that the transcript is binding to some component of the specialised posterior cytoplasm, rather than to cytoskeletal-associated elements. Cytoskeletal components may, however, play a role in localising the transcript to the posterior pole during oogenesis. In Xenopus, both microtubules and actin filaments are involved in localising maternally derived $\mathrm{Vg}-1$ transcripts to the vegetal hemisphere of the developing oocyte (Yisraeli et al. 1990).

The specialised cytoplasm at the posterior pole of the Drosophila embryo contains a large number of electron-dense organelles called polar granules (Counce, 1963; Mahowald, 1962, 1968), putative germ cell determinants. Genetic studies have identified seven genes involved in the formation of polar granules (Boswell and Mahowald, 1986; Schupbach and Wieschaus, 1986; Lehmann and Nusslein-Volhard, 1986; Manseau and Schupbach, 1989). One of these genes, vasa, has recently been cloned (Hay et al. 1988; Lasko and Ashburner, 1988), and has been shown by immunoelectron microscopy to be a component of polar granules (Hay et al. 1988). We found that the vasa protein and the cyclin B transcript are co-localised over many hours of embryogenesis. Moreover, at the blastoderm stage we have observed that cyclin B transcripts aggregate and associate with the nucleus in a manner similar to that described for polar granules (data not shown, but see similar observations of Lehner and O'Farrell, 1990). Furthermore, we found that both the vasa protein and the cyclin B transcripts at the posterior pole become dramatically concentrated in the area expected to be occupied by the microtubules associated with the nuclei that migrate to the posterior pole. This is consistent with previous observations that polar granules appear to be concentrated around centrioles to varying extents in a number of Drosophila species (Rabinowitz, 1941; Counce, 1963; Mahowald, 1968). This localisation around microtubules is much more striking than that observed for the cyclin B transcripts at the rest of the embryo cortex. This suggests that the transcripts localised to the posterior 
pole are binding to microtubules via a component in the posterior cytoplasm that has a higher affinity for microtubules than the transcript does on its own.

Although the posterior localisation of the cyclin B transcript is invariably disrupted in mutant embryos that lack polar granules, we were still able to see some posterior localisation in VLS, TUD and OSK embryos. In these cases, the transcript is initially concentrated at the posterior pole, but this concentration fades rapidly as development proceeds. This indicates that intact polar granules per se are not required for the localisation process. It is possible, however, that in this set of mutant embryos cyclin B transcripts are initially localised to the posterior pole by associating with a component (or components) of the polar granules, also initially localised to the posterior pole. Our studies and those reported previously (Lasko and Ashburner, 1990) have shown that the vasa protein is initially localised to the posterior pole in some mutant embryos. With one exception, those mutant embryos in which cyclin $B$ transcripts are localised to the posterior pole, are also those in which the vasa protein is correctly localised. It seems therefore that the processes that localise both the vasa protein and cyclin B transcripts to the posterior pole rely on similar macromolecules. While all our results are consistent with the possibility that cyclin $\mathrm{B}$ transcripts are localised to the posterior pole by binding to a component of the polar granules, it is also possible that they may bind to an as yet unidentified component of the posterior cytoplasm that is concentrated around microtubules, and whose localisation at the posterior pole is disrupted in these mutant embryos.

What is the functional significance of sequestering cyclin B transcripts into the germ line? The concentration of cyclin $B$ protein in the pole cells appears no higher than elsewhere in the late syncytial embryo (Lehner and O'Farrell, 1990; G. Maldonado-Codina, personal communication), suggesting that most of the transcript is not translated into protein at this time, but is being stored for later use. Indeed, pole cells apparently do not divide after cellularisation until much later in development when the gonads are forming (Sonnenblick, 1950). Presumably the transcript is being stored for use at this or a later time. It is unclear, however, why the embryo stores maternally supplied cyclin B transcripts, when, in principle, the gene could be transcribed in pole cells when the protein is required. Perhaps pole cells are transcriptionally inactive for a time during embryo development, and therefore need maternal cyclin B transcripts as a source of cyclin B protein to drive the later divisions of these cells. These questions could be addressed by a detailed study of the expression of the cyclin genes in relation to cell division in the germ-line during embryogenesis.

We thank Paul Lasko for generously providing the vasa antibody used in this study and for communicating results prior to publication. The mutant fly stocks were kindly donated by $C$. Nüsslein-Volhard and $P$. Lasko. We also thank Charles Girdham and Salud Llamazares for providing constructs.

\section{References}

BOOHER, R. AND BEACH, D. (1988). Involvement of $\mathrm{cdcl3}^{+}$in mitotic control in Schizosaccharomyces pombe: possible interaction of the gene product with microtubules. EMBO J. 7, 2321-2327.

Boswell, R. E. ANd Mahowald, A. P. (1985). tudor, a gene required for assembly of germ plasm in Drosophila melanogaster. Cell 43, 97-104.

Brown, N. H. and Kafatos, F. (1988). Functional cDNA libraries from Drosophila embryos. J. molec. Biol. 203, 425-437.

COUNCE, S. J. (1963). Developmental morphology of polar granules in Drosophila including observation on pole cell behavior and distribution during embryogenesis. J. Morph. 112, 129-145.

Driever, W. and Nüsslein-Volhard, C. (1988a). A gradient of bicoid protein in Drosophila embryos. Cell 54, 83-93.

Driever, W. and Nüsslein-Volhard, C. (1988b). The bicoid protein determines position in the Drosophila embryo in a concentration-dependent manner. Cell 54, 94-104.

Edgar, B. A., Kiehle, C. P. And Schubiger, G. (1986). Cell cycle control by the nucleo-cytoplasmic ratio in early Drosophila development. Cell 44, 365-372.

Edgar, B. A. ANd Schubiger, G. (1986). Parameters controlling transcriptional activation during early Drosophila development Cell 44, 871-877.

Evans, T., Rosenthal, E. T., Youngbloom, J., Distel, D. and Hunt, T. (1983). Cyclin: a protein specified by maternal mRNA in sea urchin eggs that is destroyed at each cell division. Cell 33, 389-396.

Feinberg, A. P. and Vogelstein, B. (1983). A technique for radiolabelling DNA restriction endonuclease fragments to high specific activity. Analyt. Biochem. 132, 6-13.

Feinberg, A. P. and Vogelstein, B. (1984). Addendum. Analyt Biochem. 137, 226-267.

Foe, V. E. AND AlberTs, B. M. (1983). Studies of nuclear and cytoplasmic behaviour during the five mitotic cycles that precede gastrulation in Drosophila embryogenesis. J. Cell Sci. 61, 31-70.

Hay, B., Ackerman, L., Barbel, S., Jan, L. Y. and Jan, Y. N. (1988a). Identification of a component of Drosophila polar granules. Development 103, 625-640.

HAY, B., JAN, L. Y. AND JAN, N. J. (1988b). A protein component of Drosophila polar granules is encoded by vasa and has extensive sequence similarity to ATP-dependent helicases. Cell 55, 577-587.

HunT, T. (1989). MPF, cyclin and the control of M-phase. Current Opinion in Cell Biology 1, 268-274

Ikegami, S., Taguchi, T., Ohashi, M., Oguro, M., Nagano, H. and Mano, Y. (1978). Aphidicolin prevents mitotic cell division by interfering with the activity of DNA polymerase- $\alpha$. Nature 275, 458-460.

Ingham, P., Howard, K. ANd Ish-Horowicz, D. (1985).

Transcription pattern of the Drosophila segmentation gene hairy. Nature 318, 439-445.

Karr, T. L., Weir, M. P., Al.I, Z. And Kornberg, T. (1989). Patterns of engrailed protein in early Drosophila embryos. Development 105, 605-613.

Lasko, P. F. And Ashburner, M. (1988). The product of the Drosophila gene vasa is very similar to eukaryotic initiation factor-4A. Nature 335, 611-617

Lasko, P. F. ANd Ashburner, M. (1990). Posterior localisation of vasa protein correlates with, but is not sufficient for, pole cell development. Genes and Dev. 4, 905-921

Lehman, R. and Nússlein-Volhard, C. (1986). Abdominal segmentation, pole cell formation, and embryonic polarity require the localised activity of oskar, a maternal gene in Drosophila. Cell 47, 141-152.

Lehner, C. F. ANd O'FarRell, P. H. (1989). Expression and Function of Drosophila cyclin A during embryonic cell cycle progression. Cell 56, 957-968

Lehner, C. F. ANd O'Farrell, P. H. (1990). The roles of Drosophila cyclins A and B in mitotic control. Cell 61, 535-547. 
Macdonald, P. M. and Struhl, G. (1988). Cis-acting sequences responsible for anterior localisation of bicoid mRNA in Drosophila embryos. Nature 336, 595-598.

Mahowald, A. P. (1962). Fine structure of pole cells and polar granules in Drosophila melanogaster. J. exp. Zool. 151, 201-205.

Mahowald, A. P. (1968). Polar granules of Drosophila. II. Ultrastructural changes during early embryogenesis. J. exp. Zool. 167, 237-262.

Maniatis, T., Fritsch, E. F. ANd Sambrook, J. (1982). Molecular Cloning: a Laboratory Manual. Cold Spring Harbor Laboratory.

Manseau, L. J. AND Schupbach, T. (1989). cappuccino and spire: two unique maternal-effect loci required for both the anteroposterior and dorsoventral patterns of the Drosophila embryo. Genes and Dev. 3, 1437-1452.

Merrill, P. T., Sweeton, D. And Wieschaus, E. (1988). Requirements for autosomal gene activity during pre-cellular stages of Drosophila melanogaster. Development 104, 495-509.

Minshull, J., Blow, J. J. And Hunt, T. (1989). Translation of cyclin mRNA is necessary for extracts of activated Xenopus eggs to enter mitosis. Cell 56, 947-956.

Mitchison, T. J. AND SedAT, J. W. (1983). Localisation of antigenic determinants in whole Drosophila embryos. Devl Biol. 99, 261-264.

Mohler, J. and Wieschaus, E. F. (1986). Dominant maternal effect mutations of Drosophila melanogaster causing the production of double abdomen embryos. Genetics 112, 803-822.

Murray, A. W. and Kirschner, M. W. (1989). Cyclin synthesis drives the early embryonic cell cycle. Nature 339, 275-280.

Murray, A. W., Soloman, M. and Kirschner, M. W. (1989). The role of cyclin synthesis and degradation in the control of maturation-promoting factor activity. Nature 339, 280-286

Pines, J. And Hunt, T. (1987). Molecular cloning and characterisation of the mRNA for cyclin from sea urchin eggs. EMBO J. 6, 2987-2995.

Rabinowitz, M. (1941). Studies on the cytology and early embryology of the egg of Drosophila melanogaster. J. Morph. 69, 1-49.

RafF, J. W. and Glover, D. M. (1988). Nuclear and cytoplasmic mitotic cycles continue in Drosophila embryos in which DNA synthesis is inhibited with aphidicolin. J. Cell Biol. 107, 2009-2019.

RafF, J. W. and Glover, D. M. (1989). Centrosomes, and not nuclei, initiate pole cell formation in Drosophila embryos. Cell 57, 611-619.

Riabowol, K., Draetta, G., Brizuela, L., Vandre, D. and BEACH, D. (1989). The cdc2 kinase is a nuclear protein that is essential for mitosis in mammalian cells. Cell 57 393-401.

Schupbach, T. AND Wieschaus, E. (1986). Maternal-effect mutations altering the anterior-posterior pattern of the Drosophila embryo. Roux's Arch devl Biol. 195, 302-317.
Sonnenblick, B. P. (1950). The early embryology of Drosophila melanogaster. In Biology of Drosophila. M. Demerec ed. John Wiley and sons Inc. New York

Swenson, K. I., Farrell, K. M. ANd Ruderman, J. V. (1986).

The clam embryo cyclin $A$ induces entry into $M$-phase and the resumption of meiosis in Xenopus oocytes. Cell 47, 861-870.

Swenson, K. I., Westendorf, J. M., Hunt, T. and Ruderman, J. V. (1989). Cyclins and regulation of the cell cycle in early embryos. In Molecular Biology of Ferilisation. (G. Schatten and H. Schatten eds). Academic Press, Orlando, Florida. 211-232.

Tautz, D. And Pfeiffe, C. (1989). A non-radioactive in situ hybridisation method for the localisation of specific RNAs in Drosophila embryos reveals translational control of the segmentation gene hunchback. Chromosoma 98, 81-85.

Verde, F., Labbe, J-C., Doree, M. and Karsenti, E. (1990). Regulation of microtubule dynamics by cdc2 protein kinase in cell free extracts of Xenopus eggs. Nature 343, 233-238.

WARN, R. (1986). Microtubule organisation during polar cap mitosis and pole cell formation in the Drosophila embryo. In Progress in Developmental Biology, Part B, Alan R. Liss, Inc. pp. 361-364.

WARN, R. M., Smith, L. AND WARN, A. (1985). Three distinct distributions of F-actin occur during the divisions of polar surface caps to produce pole cells in Drosophila embryos. $J$. Cell Biol. 100, 1010-1015.

Westendorf, J. M., Swenson, K. I. and Ruderman, J. V. (1989). The role of cyclin B in meiosis. J. Cell Biol. 108, 1431-1444.

Whitfield, W. G. F., Gonzalez, C., Maldonado-Codina, M. G. AND Glover, D. M. (1990). The A- and B-type cyclins of Drosophila are accumulated and destroyed in temporally distinct events that define separable phases of the $\mathrm{G} 2-\mathrm{M}$ transition. EMBO J. 9, 2563-2572.

Whitfield, W. G. F., Gonzalez, C., Sanchez-Herrero, E. and Glover, D. M. (1989). Transcripts of one of two Drosophila cyclin genes become localised in pole cells during embryogenesis. Nature 338, 337-340.

Wieschaus, E. AND SweEton, D. (1988). Requirements for Xlinked-zygotic gene activity during cellularisation of early Drosophila embryos. Development 104, 483-493.

Yisraeli, J. K., Sokol, S. and Melton, D. A. (1990). A two step model for the localisation of maternal mRNA in Xenopus oocytes: Involvement of microtubules and microfilaments in the translocation and anchoring of Vg1 mRNA. Development 108, 289-298.

ZaloKAR, M. AND ERK, I. (1976). Division and migration of nuclei during early embryogenesis of Drosophila melanogaster. J. Microbiol. Cell 25, 97-106.

(Accepted 7 September 1990) 